\title{
Pemanfaatan Barang Bekas sebagai Alat Peraga Edukasi Ramah Lingkungan Sekolah PAUD di Kota Yogyakarta
}

\author{
Utilization of Used Goods as Environmental Friendly Educational Teaching Tools for Early \\ Childhood Schools in Yogyakarta
}

Dewi Sekar Kencono*
Atik Septi Winarsih
Department of Governmental Science,
Universitas Muhammadiyah
Yogyakarta, Bantul, Special Region of
Yogyakarta, Indonesia
email: dewisekarkencono@umy.ac.id
Kata Kunci
Alat peraga edukasi
Barang bekas
Kreativitas
PAUD
Keywords:
Educational props
Used goods
Creativity
Early childhood education programs
Received: January 2021
Accepted: March 2021
Published: April 2021

\begin{abstract}
Abstrak
Tulisan ini memiliki tujuan menunjukkan pentingnya alat peraga edukasi yang ramah lingkungan dengan memanfaatkan barang bekas. Pelaksanaan kegiatan belajar mengajar di PAUD Kota Yogyakarta mengalami permasalahan dengan keterbatasan alat peraga edukasi (APE). Keberadaan APE menjadi salah satu kunci dalam melaksanakan proses pembelajaran. Masih rendahnya kreativitas guru dalam membuat APE dalam hal ini menjadi kedala untuk menyediakan APE untuk proses pembelajaran. APE ini bisa dibuat dengan meningatkan kreativitas antara guru dan orangtua wali murid. Selama masa pandemi Covid-19, kegiatan belajar mengajar di PAUD dilaksanakan di rumah masing-masing. Untuk mendukung penggunaan APE, dilakukan pelatihan pemanfaatan barang bekas. Melalui pelatihan pemanfaatan barang bekas, bertujuan memanfaatkan barang di sekitar dan dijadikan media pembelajaran anak untuk guru dan orang tua. Selain itu, untuk meningkatkan kreativitas guru dan orang tua. Penggunaan barang-barang bekas didaur ulang menjadi barang-barang yang bermanfaat. Pemanfaatan barang bekas mengurangi limbah sampah yang semakin meningkat. Melalui pelatihan pemanfaatan barang bekas menjadi alat peraga edukasi, dapat mempermudah cara pembelajaran baik di rumah dan sekolah untuk anak usia dini dan mengurangi limbah barang bekas.
\end{abstract}

\begin{abstract}
This paper has the aim of demonstrating the importance of environmentally friendly educational props by utilizing used goods. The implementation of teaching and learning activities at Pre-Kindergarten Kota Yogyakarta has problems with limited educational aids (APE). The existence of APE is one of the keys in carrying out the learning process. The low level of teacher creativity in making APE, in this case, becomes the anchor to provide APE for the learning process. This APE can be made by enhancing the creativity between teachers and parents of parents. During the Covid-19 pandemic, teaching and learning activities in PreKindergarten were carried out in their respective homes. To support the use of APE, training on the use of used goods was conducted. Through training in the use of used goods, the aim is to utilize items around and be used as children's learning media for teachers and parents. In addition, to increase the creativity of teachers and parents. Used goods are recycled into useful items. The use of used goods reduces the increasing waste of waste. Through training on the use of used goods as educational props, it can facilitate learning methods both at home and school for early childhood and reduce waste of used goods.
\end{abstract}

\section{PENDAHULUAN}

Alat Peraga Edukasi (APE) merupakan media atau alat yang digunakan untuk mendidik dan mengajar dalam rangka menyampaikan konsep dalam kurikulum kepada peserta didik yang diajarkan oleh guru. Tujuan menggunakan alat peraga edukasi ini adalah 
mengefektifkan proses pembelajaran agar materi atau informasi yang disampaikan lebih mudah dimengerti dan dipahami oleh siswa melalui bahan yang sederhana dan dapat diperoleh secara mudah di lingkungan sekitar siswa (Juwairiah, 2013; Kurniawati \& Atmojo, 2017). Selain itu, penggunaan alat peraga edukasi bertujuan agar kompetensi yang dimiliki siswa dapat tercapai sebagaimana telah ditetapkan dalam kurikulum pembelajaran. Melalui alat peraga edukasi, guru bisa melakukan proses pembelajaran yang lebih efektif dan efisien dalam menyampaikan konsep dan materi (Nurrita, 2018).

Menurut Widiyatmoko dan Pamelasari (2012), alat peraga edukasi adalah perantara atau pengantar dalam proses pembelajaran. Alat peraga edukasi menjadi alat untuk merangsang panca indra, motorik, afektif, menciptakan rasa, akal pikiran, dan respon dari siswa terhadap materi pembelajaran (Taufiq et al., 2014; Kurniawati \& Atmojo, 2017). Penggunaan alat peraga pembelajaran ini menjadi media komunikasi yang tercipta antara guru dan siswa untuk menciptakan interaksi dalam proses belajar mengajar (Arsyad, 2005). Perkembangan pendidikan saat ini sangat masif dan sudah dimulai dari anak-anak berusia 1 tahun dengan kelompok bermain (KB) dan pendidikan anak usia dini (PAUD). Anak-anak yang masih membutuhkan pengenalan dan mengasah sensorik kasar dan kognitif memerlukan media untuk tumbuh kembang pendukung (Hidayanti, 2019). Tujuan proses pembelajaran adalah merangsang sensorik kasar dalam saraf mata dengan mengenal warna, perlu alat-alat permainan dengan berbagai macam warna. Selanjutnya, dalam proses mengasah sensor dan mengenal bentukbentuk diperlukan berbagai macam media baik kain, kayu, maupun kertas untuk mengenal berbagai bentuk. Dengan alas an tersebut, alat peraga edukasi dapat menjadi alternatif media pembelajaran untuk anak-anak (Hasanah, 2016).

Alat peraga edukasi pada pendidikan anak di bawah sekolah dasar (SD) terdiri atas dua macam, yaitu alat peraga edukasi dalam dan luar. Alat peraga edukasi merupakan alat permainan yang dirancang dan digunakan agar anak-anak dapat bermain dan belajar sehingga ada peningkatan dalam aspek perkembangan anak. Anak usia dini akan lebih nyaman belajar jika diikuti dengan gerakan dan permainan. Melalui proses belajar mengajar di PAUD, anak juga harus dilatih kemampuan verbal dan bahasa, alat peraga edukasi ini sangat baik jika diiringi dengan dengan komunikasi yang baik seperti dialog atau dongeng kepada anak. Hal ini sangat baik karena dapat meningkatkan kemampuan berbahasa, sosialisasi dan komunikasi anak dengan temannya dan gurunya (Hijriati, 2017).

Keberadaan alat peraga edukasi luar sudah mencukupi seperti prosotan, jungkat-jungkit, ayunan, dan lain sebagainya. Alat peraga edukasi dalam ini meliputi sarana prasarana peraga, seperti bentuk bangun, warna, balok, puzzle dan alat perlengkapan mewarnai. Usia guru yang masih muda menjadi pendukung untuk meningkatkan kreativitas dalam melaksanakan pembalajaran yang edukatif dan inovatif dalam memanfaatkan media di lingkungan sekitar. Media pembelajaran yang baik adalah penyelarasan kurikulum dengan kreativitas yang dihasilkan guru untuk menunjang proses pembelajaran (Sanjaya, 2013; Murdiyanto \& Mahatama, 2014; Rangkuti et al., 2019).

Keterbatasaan alat peraga edukasi dalam pada PAUD Kota Yogyakarta dikarenakan keterbatasan biaya dan minimnya sumbangan yang diterima PAUD. Keberlangsungan proses belajar mengajar menjadi tanggung jawab dan sharing bersama antara guru dan wali murid yang dilakukan bergantian. Keberadaan tenaga pengajar yang sedikit juga mempengaruhi 
kreativitas yang dilakukan oleh guru. Kesempatan untuk membuat alat peraga edukasi yang berbasis bahan bekas terbatas oleh waktu dan kreativitas. Oleh karena itu, pemanfaatan barang-barang bekas sekitar kurang diperhatikan sebagai sarana pembuatan alat peraga edukasi. Keadaan di lapangan menunjukan guru memiliki keterbatasan dalam menciptakan APE sehingga menjadi monoton dan kurang inovatif dalam menyampaikan pembelajaran kepada siswa (Irfandi et al., 2018; Rangkuti et al., 2019).

Masa pandemi Covid-19 yang terus berlangsung dari awal tahun 2020 memaksa anak-anak didik untuk belajar di rumah. Permasalahan proses belajar yang dihadapi menjadi semakin kompleks baik dari guru maupun orang tua wali murid di tengah proses belajar di rumah. Keadaan ini menuntut kreativitas orang tua dan guru untuk menciptakan media pembelajaran kepada anakanak. Solusi dari permasalahan ini adalah dengan pengumpulan dan mendayagunakan barang bekas dari lingkungan sekitar untuk dibuat menjadi alat peraga edukasi. Penggunaan barang bekas ini juga untuk turut mengurangi limbah yang tidak bisa diurai dengan cepat demi kelestarian bumi. Solusi yang tersebut dilakukan dengan cara pelatihan pembuatan alat peraga dengan bahan bekas yang berada di lingkungan sekitar.

Tujuan kegiatan pengabdian kepada masyarakat ini adalah mengenalkan penggunaan barang bekas untuk membuat alat peraga edukasi pada kelompok bermain (KB) dan pendidikan anak usia dini (PAUD) di tengah keterbatasan alat peraga terutama dalam masa pandemi Covid-19. Metode yang digunakan adalah penyelesaian masalah mitra yaitu ketersediaan alat peraga edukasi pada sekolah PAUD di Kota Yogyakarta melalui pelatihan pembuatan alat peraga edukasi dari barang bekas. Pelatihan ini melibatkan guru dan orang tua wali murid untuk mendukung kreativitas dalam pembuatan alat peraga edukasi secara mandiri.

\section{METODOLOGI}

Metode pelaksanaan pengabdian kepada masyarakat untuk menyelesaikan permasalahan mitra dengan menggunakan metode pelatihan dan pendampingan. Permasalahan yang dihadapi mitra, yaitu:

1. Keterbatasan keberadaan alat peraga edukasi

2. Keterbatasan dan minimnya kreativitas dalam membuat alat peraga edukasi sehingga proses pembelajaran kurang berkembang dan monoton

3. Keadaan pandemi memaksa siswa untuk belajar dari rumah sehingga peran guru lebih banyak diambil oleh orang tua murid dalam proses belajar mengajar.

Penyelesaian masalah yang dihadapi mitra melalui pendekatan permasalahan dari yang utama melalui tahapan sebagai berikut.

1. Tahapan persiapan

Melakukan pemetaan masalah yang dihadapi oleh mitra Paguyuban PAUD Kota Yogyakarta melalui survei. Selanjutnya, melakukan pembuatan proposal kegiatan pengabdian. Proposal tersebut diajukan kepada LP3M Universitas Muhammadiyah Yogyakarta untuk konsultasi, koordinasi dan izin dalam pelaksanaan kegiatan pengabdiaan. Menyampaikan surat izin untuk melakukan kegiatan pengabdian kepada masyarakat yaitu Paguyuban PAUD dan perwakilan orang tua murid. Pada saat penyampaian ini, melakukan diskusi dengan pihak Paguyuban PAUD untuk sosialisasi pelatihan, tempat, dan waktu kegiatan pelatihan.

2. Tahap Pelakasanaan

Pelaksanaan kegiatan dilakukan pada bulan Juli 2020. Pelatihan dilakukkan dengan membuat boneka dari kaos kaki bekas, ayam dari cangkang telur, sapi dari botol susu bekas, dan pesawat dari sendok bekas. Pendampingan dilakukan sampai mitra bisa membuat sendiri dan melakukan kreasi pada model yang diajarkan. 


\section{Tahapan evaluasi}

Setelah pelatihan berlangsung, untuk melihat keberhasilan kegiatan pengabdian kepada masyarakat, dilakukan evaluasi pelaksanaan program, yaitu kualitas alat peraga edukasi dan kreativitas guru dalam memberikan media pembelajaran (melalui tugas di rumah kepada siswa), serta tanggapan kepala sekolah, guru, dan orang tua terhadap pelaksanaan kegiatan pengabdian masyarakat.

\section{HASIL DAN PEMBAHASAN}

Kegiatan pengabdian kepada masyarakat yang dilakukan dari bulan Maret-September 2020. Kegiatan ini melalui beberapa tahapan dalam pelaksanaannya sebagai berikut. Persiapan, tim pelaksana melakukan survei permasalahan yang dihadapi oleh mitra. Melalui survei, diketahui permasalahan utama yang dihadapi oleh mitra. Tim pengabdi membuat proposal kegiatan, melakukan koordinasi, dan izin dari LP3M Universitas Muhammadiyah Yogyakarta. Izin yang telah diperoleh kemudian dikomunikasi dengan mitra untuk pelaksanaa kegiatan. Melaui proses identifikasi masalah, diperoleh kesepakatan pelaksnaan kegiatan, antara lain:

1. Kegiatan pelatihan akan dilangsungkan pada bulan Juli 2020 di Balai Pertemuan Warga Kalurahan Notoprajan Kota Yogyakarta

2. Kegiatan diikuti oleh perwakilan dari PAUD Kota Yogyakarta dan orang tua murid

3. Menerapkan jaga jarak dan protokol kesehatan.

Pelaksanaan, kegiatan pengabdian kepada masyarakat diawali dengan sambutan ketua pengabdian. Kemudian pelatihan diisi oleh narasumber Ibu Tashia dari Little Bee Nitipuran Juara Lomba Pembuatan Alat Peraga Edukasi untuk anak usia PAUD. Pada saat pelaksanaan, setiap peserta dibekali paket alat tambahan untuk menjadi penghias media utama. Barang bekas yang wajib dibawa oleh peserta adalah kaus kaki bekas layak, botol bekas susu kecil, cangkang telur, dan sendok plastik bekas yang sudah dicuci bersih. Peserta terlihat antusias dalam mengikuti pelatihan.

Pada pelatihan ini, dibuat tiga tema yaitu membuat boneka kaos kaki, membuat hewan (ayam dan sapi), dan alat transportasi (pesawat terbang). Pemilihan tema ini memiliki maksud dan tujuan tersendiri. Tema boneka kaos kaki digunakan sebagai media untuk peraga manusia dan hewan sehingga anak didik memiliki gambaran dalam komunikasi dan memperagakan cerita yang disampaikan guru atau orang tua. Tema kedua adalah pembuatan hewan dari botol bekas dan cangkang telur. Tema ini dipilih untuk mengajarkan kreativitas mewarnai dan menempel pada anak dan merangsang anak untuk lebih kreatif dalam memadu dan padankan warna dalam aplikasi pembuatan. Melalui tema ini, guru dan orang tua dapat menggunakan alat peraga edukasi untuk bercerita dan mendongeng atau menjelaskan proses perkembang biakan dan tumbuh kembang hewan. Tema ketiga adalah alat transportasi. Tema ini dipilih untuk menjelaskan transportasi yang digunakan setiap hari. Selain itu, menjelaskan pergerakan dari atas ke bawah dengan secara mudah kepada anak didik.

Kegiatan selanjutnya adalah praktik yang dilaksanakan oleh peserta sehingga terampil menggunakan bahan yang telah disediakan. Melihat bagaimana kesulitan yang dihadapi dalam membuat alat peraga edukasi oleh guru dan orang tua murid yang mengikuti pelatihan.

Selama proses kegiatan workshop secara aktif peserta bertanya tahapan proses dalam pembuatan alat peraga edukasi dan kegunaan alat tersebut. Workshop tersebut bertujuan mengajak peserta berkreasi sesuai keinginan dengan bekas dan pendukung. Hasilnya para peserta mampu membuat alat peraga edukasi secara mandiri dan mendukung proses belajar untuk anak usia dini. 
Dokumentasi seluruh kegiatan pengabdian disajikan pada Gambar 1 sampai 7.

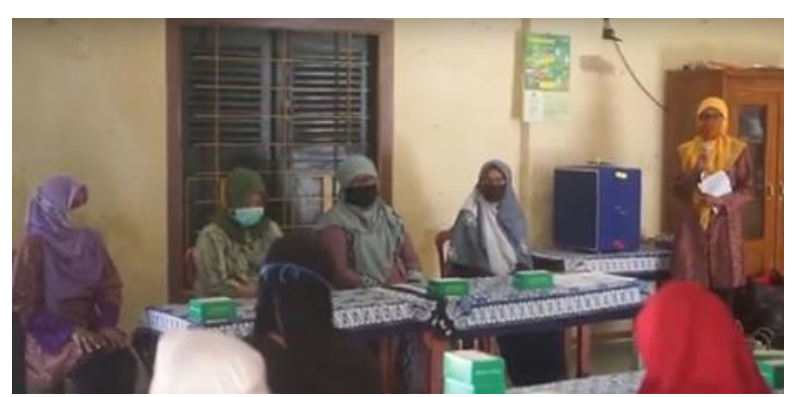

Gambar 1. Sambutan Ibu Ketua Paguyuban PAUD Kota Yogyakarta

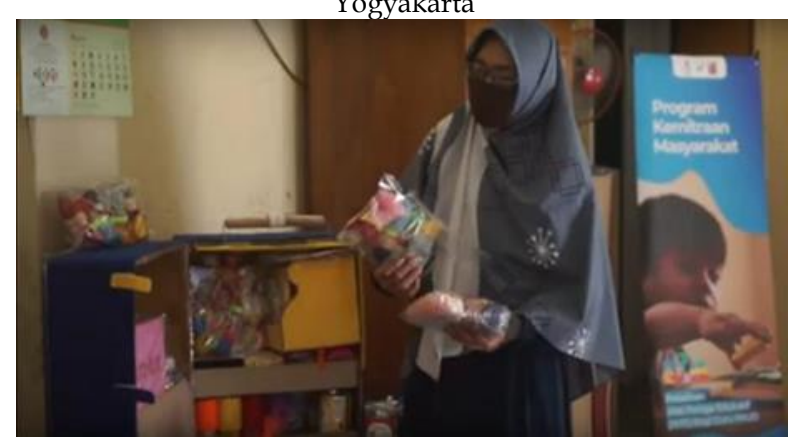

Gambar 2. Penjelasan Narasumber terkait bahan yang akan digunakan dalam pembuatan alat peraga edukasi

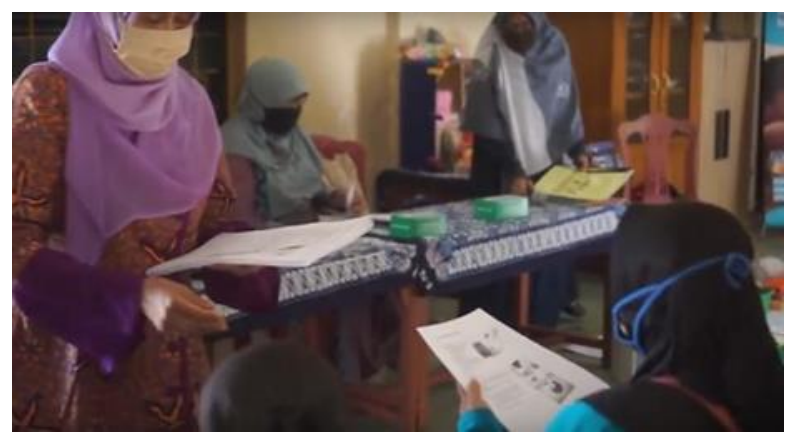

Gambar 3. Sosialisasi tahapan pembuatan alat peraga edukasi kepada para peserta

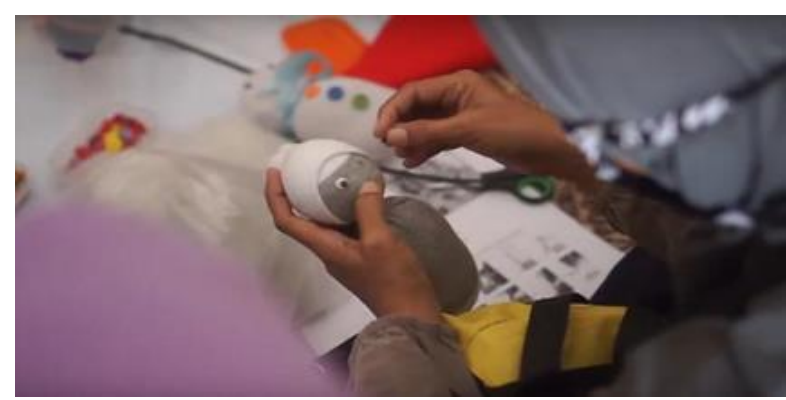

Gambar 4. Workshop Pembuatan Alat Peraga Edukasi Pembuatan boneka kaos kaki

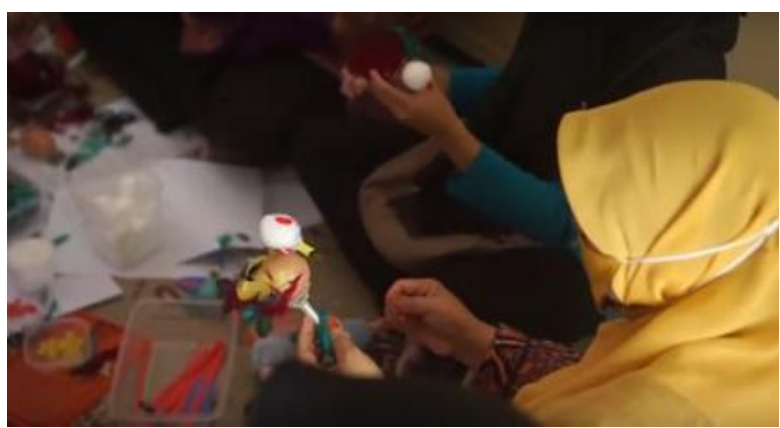

Gambar 5. Workshop Pembuatan Alat Peraga Edukasi Pembuatan hewan

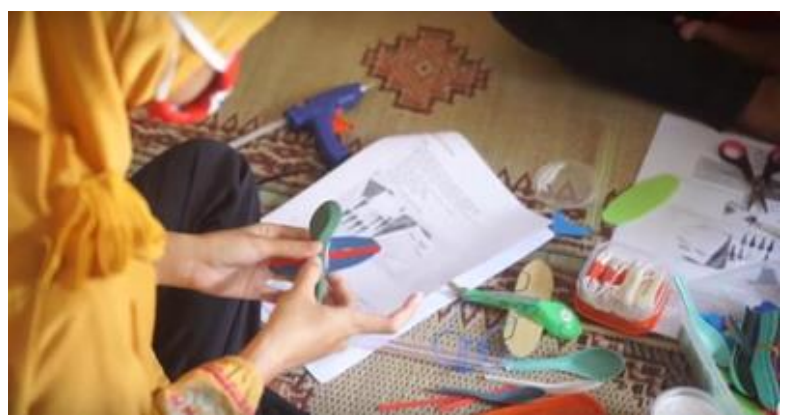

Gambar 6. Workshop Pembuatan Alat Peraga Edukasi Pembuatan alat transportasi

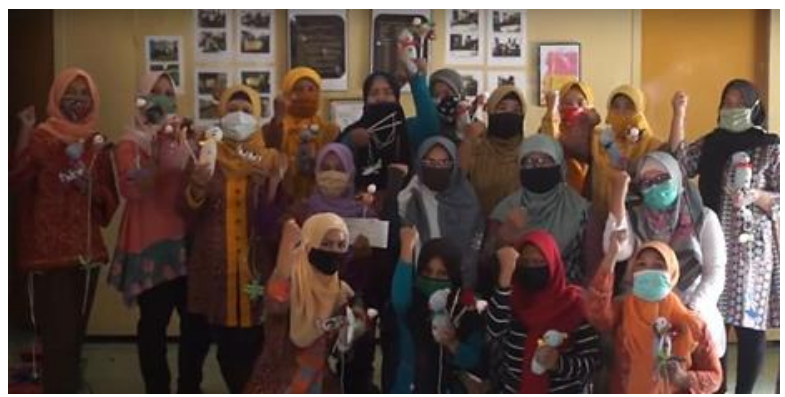

Gambar 7. Peserta dengan hasil karyanya

Evaluasi kepada para peserta dilakukan setelah kegiatan berlangsung. Ketua Paguyuban PAUD Kota Yogyakarta Ibu Soraya menyatakan bahwa kegiatan pengabdian kepada masyarakat dengan membuat alat peraga edukasi ini sangat menolong di tengah proses pembelajaran secara daring dan anak didik yang berada di rumah. Orang tua murid dari beberapa PAUD juga menyampaikan melalui ketua paguyuban, bahwa anakanak jadi lebih kreatif di rumah dan komunikasi dengan orang tua melalui peraga sangat memuaskan. Terlebih bagi orang tua yang bekerja tentunya memiliki keterbatasan waktu dalam mendampingi anak-anak 
dalam belajar dari rumah. Melalui pelatihan pembuatan alat peraga edukasi ini, diharapkan dapat mempermudah orang tua wali murid memberikan pemahaman kepada anak-anak selama di belajar dari rumah.

\section{KESIMPULAN}

Program pengabdian kepada masyarakat dengan pelatihan pembuatan alat peraga edukasi pada anak peserta PAUD menjawab keterbatasan alat peraga edukasi yang dimiliki oleh penyelenggara PAUD. Kegiatan PKM ini menjadi solusi untuk secara mandiri dalam upaya penyampaian pembelajaran kepada peserta didik. Guru dapat lebih dini dalam mempersiapkan bahan untuk pembelajaran kepada anak-anak. Melalui pemanfaatan barang bekas, akan tercipta alat peraga edukasi yang ramah lingkungan dan murah, serta mengurangi sampah yang masih bisa dimanfaatkan.

\section{UCAPAN TERIMA KASIH}

Ucapan terima kasih kami sampaikan kepada Lembaga Penelitian Publikasi dan Pengabdian Masyarakat Universitas Muhammadiyah Yogyakarta (LP3M UMY) telah memberikan dana untuk melaksanakan rangkaian kegiatan pengabdian kepada masyarakat. Ucapan terimakasih kami sampaikan kepada Ketua Paguyuban PAUD Kota Yogyakarta yang telah mengizinkan kegiatan pengabdian kepada masyarakat ini dilaksanakan.

\section{REFERENSI}

Arsyad, A. 2005. Media Pembelajaran. Jakarta: Tim Abdi Guru Erlangga.

Hasanah, U. 2016. Pengembangan Kemampuan Fisik Motorik Melalui Permainan Tradisional Bagi Anak Usia Dini. Jurnal Pendidikan Anak.
5(1):717-733.

https://doi.org/10.21831/jpa.v5i1.12368

Hidayanti, M. 2019. Kesiapan Sekolah Anak Kelompok Bermain Berbasis Model Pembelajaran Sentra. Publicitas. 13(1):1-19.

Hijriati. 2017. Peranan Dan Manfaat APE Untuk Mendukung Kreativitas Anak Usia Dini. Bunayya: Jurnal Pendidikan Anak. 3(2):59-69.

Irfandi, Faisal, Hasibuan, N.I., Panggabean, D.D. 2018. The Dissemination of Technology-Based Learning Media for Elementary School Teachers in the District of Sijunjung. JCRS (Journal of Community Research and Service). 2(1):198-205.

https://doi.org/10.24114/jcrs.v2i1.10491

Juwairiah. 2013. Alat Peraga Dan Media Pembelajaran Kimia. $\quad$ Visipena. 4(1):1-13. https://doi.org/10.46244/visipena.v4i1.85

Kurniawati, W., Atmojo, S.E. 2017. Pembelajaran Sains Bermuatan Karakter Ilmiah Dengan Alat Peraga Barang Bekas Dan Asesmen Kinerja. Jurnal Pendidikan Indonesia. 6(1):49-59. http://dx.doi.org/10.23887/jpiundiksha.v6i1.8866

Murdiyanto, T., Mahatama, Y. 2014. Pengembangan Alat Peraga Matematika Untuk Meningkatkan Minat Dan Motivasi Belajar Matematika Siswa Sekolah Dasar. Sarwahita: Jurnal Pengabdian Kepada Masyarakat. 11(1):38-43. https://doi.org/10.21009/sarwahita.111.07

Nurrita, T. 2018. Pengembangan Media Pembelajaran Untuk Meningkatkan Hasil Belajar Siswa. Misykat: Jurnal Ilmu-ilmu Al-Qur'an, Hadist, Syariah dan Tarbiyah. 3(1):171-187. http://dx.doi.org/10.33511/misykat.v3n1.17 1

Rangkuti, M.A., Manurung, I.F.U., Tarigan, N., Panggabean, D.D., Irfandi, Harahap, M.H., Syah, D.H. 2019. Pendampingan Guru-Guru Sekolah Dasar Mendesain Pembelajaran Tematik Berbasis Alat Peraga Di Kecamatan Medan Helvetia. Publikasi Pendidikan: Jurnal Pemikiran, Penelitian dan Pengabdian Masyarakat Bidang Pendidikan. 9(3):232-239. https://doi.org/10.26858/publikan.v9i3.1029 6 
Sanjaya, W. 2013. Kurikulum dan Pembelajaran: Teori dan Praktik Pengembangan Kurikulum Tingkat Satuan Pendidikan (KTSP). Jakarta: Kencana Prenada Media Group.

Taufiq, M., Dewi, N.R., Widiyatmoko, A. 2014. Pengembangan Media Pembelajaran Ipa Terpadu Berkarakter Peduli Lingkungan Tema Konservasi Berpendekatan ScienceEdutainment. Jurnal Pendidikan IPA Indonesia. 3(2):140-145.

https://doi.org/10.15294/jpii.v3i2.3113

Widiyatmoko, A., Pamelasari, S.D. 2012. Pembelajaran Berbasis Proyek Untuk Mengembangkan Alat Peraga IPA Dengan Memanfaatkan Bahan Bekas Pakai. Jurnal Pendidikan IPA Indonesia. 1(1):51-56. https://doi.org/10.15294/.v1i1.2013 